\title{
University Students' Perceptions of Standard-Based English Language Learning Outcome
}

\author{
Pham Thi Tuyet Nhung \\ Department of French, University of Foreign Languages, Hue University, Hue, Vietnam
}

Email address:

pttnhung@hueuni.edu.vn

\section{To cite this article:}

Pham Thi Tuyet Nhung. University Students' Perceptions of Standard-Based English Language Learning Outcome. International Journal of Language and Linguistics. Vol. 7, No. 6, 2019, pp. 315-318. doi: 10.11648/j.ij11.20190706.19

Received: September 17, 2019; Accepted: October 14, 2019; Published: November 9, 2019

\begin{abstract}
On the implementation level of the National Foreign Languages Project, the Vietnamese Ministry of Education and Training (MOET) has set new language learning outcomes for different educational levels from primary education to tertiary education based on different levels of proficiency of the Common European Framework for Reference of Languages by the Council of Europe (2001) (the CEFR). As a result of the adoption of the CEFR to set learning standards, university students who are majored in a foreign language must obtain evidence of their proficiency in that language at least at $\mathrm{C} 1$ level in their first foreign language and $\mathrm{B} 1$ level in a second foreign language as pre-requisite to be awarded university graduation degree. This paper reports a study on university French-majored students' perceptions of the CEFR-A1, A2, and B1 standard-based English language learning outcomes and the problems they face while trying to achieve these learning outcomes. The findings have shown that the investigated students have limited understanding of the standards expected of them and tend to associate the required learning outcomes with the test results rather than the development of their own language skills. The study has also revealed common problems the students faced during the implementation of the the standard-based learning outcome policy.
\end{abstract}

Keywords: Standard-Based, Learning Outcome, CEFR, Perception

\section{Introduction}

\subsection{The Adoption of the CEFR in English Education in Vietnam}

In the current trend of globalization, English has become the most preferred foreign language at all educational levels in Vietnam [11, 12, 15]. However, for decades since the introduction of English into the educational curriculum in Vietnam, it has been widely recognized that a majority of English students still cannot communicate well in English after spending years learning it at school and even at university although they may have accumulated a good knowledge of grammar and vocabulary [6]. In a national effort to improve the quality of teaching and learning foreign languages, primarily English in the state-run educational system, in 2008 the Vietnamese government launched a national project titled Teaching and learning foreign language in the state-run educational system for the 2008-2020 period, which is now extended to 2025 .

As a large-scale language reform policy, the national project has been seen as the most ambitious endeavour in Vietnam's history funded by the government $[8,10]$. Central to the operation of the 2020 Project is the adoption of the Common European Framework of Reference for Languages [2] to set language learning outcomes at all educational levels from primary to tertiary. According to this new standard-based learning outcome system, university students majored in English language (e.g. English language education or translation) must achieve at least the CEFR-C1 level (described as independent language user) as a pre-requisite condition for their university degree to be granted. Students who are not majored in English are required to obtain the CEFR-B1 (described as the threshold level) as an "exit" condition.

\subsection{Implementing the CEFR-Based Learning Outcomes for Non-English Majors}

Universities have received directives and guidance from the MOET to innovate their foreign language curriculum, teaching materials, teaching methodology and assessment practice in order to help their non-English majored students 
achieve the CEFR-B1 level [8], the Threshold level where language users are believed to have the ability to perform fundamental functions in the language - as a minimum English language proficiency. Teachers and students have nevertheless, expressed their doubt about the achievability of level B1 by non-English major students [11]. The main reason lies with the inadequate contact hours that university programs provide for foreign language learning. It is estimated to take from 350 to 400 contact, teacher-led hours of instruction to obtain the CEFR B1 level [3]. Nevertheless, according to the MOET's guidelines, non-English majors only have 7 credits in their programme for general English, which is equivalent to 105 contact hours totally, with 15 hours per credit. After these 105 general English instruction hours, students may have the chance to enter a 30-hour English for specific purposes course (ESP), which is optional, depending on their program and major [11]. Research on applying the CEFR or its use in an English-as-a-foreign language context like Vietnam and on learners' perceptions of the language standard-based learning outcome remains very rare. On the other hand, research on learning outcome suggests that learning outcomes may become too aligned to managerial and audit processes, and so are less useful to teachers and students $[5,6]$. Research on students' understanding of the learning outcome they are expected to achieve remains limited [4]. This study aiming to explore how French-majored students perceive the CEFR-B1 level of proficiency in English as their second foreign learning outcome is therefore, necessary.

\section{The study}

\subsection{Research Question}

This study seeks the answer the following questions:

1. What are French-majored students' perceptions of the CEFR-based proficiency levels (A1, A2, B1) as their English language learning outcome?

2. What problems do they face while trying to achieve these learning outcomes?

\subsection{Participants}

The participants of this research are 19 university students majored in French. They have 3 courses of general English. The first course is delivered in their first semester of their first year, expected to get them A1 level; second course in their second semester of the first year getting them A2 level and the third last course in their first semester of their second year hoped to get them B1 as described in the syllabus of these courses. The participants were in the first semester of the second year of their program at the time this study was conducted. They had finished 60 teacher-led hours in English classes and were in their third course of general English of 45 hours. Four (4) of them are male and the other 15 female in the age range of 19 and 20.

\subsection{Data Collection Methods}

The study employs open-ended questions in the form of written report to explore students' perceptions of the learning outcome they are expected to achieve, the problems they encountered while learning for this outcome. The report includes 5 main items. The first item asks the participants to describe the required learning outcomes for each learning semester, ranging from semester 1 to 3 . The second item asks the participants to write down what achieving the CEFR-B1 level means (literally what they can do with the English language at this level). The third item asks the participants to describe the problems they face while learning for this expected outcome. Item 4 explores their suggestions towards a better implementation of this standard-based learning outcome.

\section{Results}

\subsection{Students' Perceptions}

This section describes and interprets our analysis of the data provided by the participants in their written reports.

\subsubsection{Students' Perceptions of Learning Outcomes}

Four tendencies have emerged from the participants' report concerning their perceptions of the expected learning outcomes. The participants have a limited understanding of the standard-based learning outcomes, associating the expected outcomes with their passing end-of-semester test, considering the standard-based learning outcomes as abstract notions and assuming that the proficiency levels of A1, A2, and $\mathrm{B} 1$ are just simply the end-of-semester tests.

Limited understanding of the standard-based language learning outcome

When requested to describe their understanding of the expected learning outcome of each semester, the participants indicated a common understanding that they were asked to develop the ability to use English with 4 skills, including reading, writing, listening and speaking as well as to learn vocabulary and language structures across levels/learning outcomes. Up to 14 our of 19 students mentioned A1, A2, and B1 levels as the expected learning outcomes respectively for semester 1, 2 and 3 in their university program. However, there is very little information indicating that the participants understand clearly what each required level of proficiency (i.e. A1, A2, and B1) involves or indicates. They also failed to describe in details the degree of proficiency to which they are expected to perform those skills. Specifically they could not state clearly what they can do for each level of proficiency.

Associating the expected learning outcome with passing the test $(s)$

The participants had the tendency to associate the required learning outcomes with the end-of-semester tests. The participants' common response to the request which asked them to describe the learning outcomes is that they need to pass the end-of-semester test of English A1, English A2, and English B1. Passing the test at the end of each semester is repeated quite frequently in various participants' written reports, which shows that they are very much concerned about the test(s). Instead of perceiving learning outcome as the 
ability to use the language at a specific level (i.e., what they can do with the language), the participants equated learning achievement with the test scores.

Associating the learning outcome with the degree of completing the textbooks

Another prevailing dominant tendency found in the students' response to the request to describe their required learning outcome is their frequent reference to covering or completing the required textbooks. "Finishing the textbooks" or "Finishing units/lessons in the textbooks" is cited as the second most popular wish after passing end-of-semester tests. This suggests that to many students, the required learning outcome literally means covering all the lessons and units in the textbook, not developing language ability.

Standard-based learning outcomes as abstract notions

When asked to describe what it means by the CEFR-A1, A2 and B1 levels, a majority of the students failed to provide relevant descriptions of these levels of proficiency. Their responses show that to them $\mathrm{A} 1, \mathrm{~A} 2, \mathrm{~B} 1$ are not really levels of proficiency but rather abstract notions used to label English courses ranging from English A1 (semester 1), English A2 (semester 2) to English B1 (semester 3). A1, A2 and B1 are perceived as course names and again associated with specific textbook volumes in the textbook series.

Assuming that the CEFR-A1, A2, B1 level are names of tests Requested to write down the standard-based learning outcomes for general English curriculum, a majority of the students surveyed responded by writing down B1 level. However, in their responses this level of proficiency was associated with a test, called B1 test. A typical description is "The required learning outcome of the general English curriculum is level B1. We need to pass this test when we finish the program [of general English at the end of the third semester]." This finding is in line with previous findings regarding the participants' understanding that A1, A2 and B1 are just tests and notions used to name courses rather than degrees of ability to use language.

\subsubsection{Problems Students Faces While Trying to Achieve the Standard-Based Learning Outcome}

A number of problems have been reported by the participants.

\section{Limited contact hours}

The most frequently reported problem raised by the participants is that they do not have enough time to learn English as a second foreign language. They only have 2 in-class hours per week for the first 2 semesters and 3 hours for the third semester of their program, which to them is not sufficient for obtaining the required level of proficiency. This problem is often cited to make the situation worse when there are students of different levels of proficiency in one same class and there are too many students in the class.

The B1-level test is too difficult

The second most commonly cited problem is the B1-level test is too difficult. The participants expressed the concern about the consequences of failing the B1-level test. The biggest concern is about the use of B1-level test for gatekeeping purpose. Popular questions include: What if I can't have B1 level certificate by the time I graduate from the university? Why do I need to pass this test while I don't use much English in my field (this is most often asked by students major in Primary Education)?, If I fail the B1-level test, when can I get my university graduation degree? and How come I pass this test when I only learn English in the first 3 semester (and do not learn it in the last 5 semesters of my program)?

Mismatch between instruction and assessment

The participants appreciated the teaching methodology but put a stress on what they considered as mismatch between the instruction content and assessment. Common comments are as follows: There is little coherence and/or parallel between the instruction content, the tasks in the textbooks and the tasks in the end-of-semester tests. This is understandable as the students expect they are assessed on what they learnt (i.e., achievement tests) but end-of-semester tests are currently designed following proficiency test format, which mimic standardized international tests and much differ from the language tasks included in the textbook series. Student responses suggest that assessment is very much independent of courses and teachers, and that grades are not always indicative of what is learned in classes, suggesting that more could be done institutionally and in classrooms to better align what teachers intend to teach and what students expect to learn. The data also indicate that a considerable number of students struggle to understand from their learning outcomes the level of learning required to pass assessments.

The validity of $B 1$ level certificate

The participants expressed a great consideration for the validity and recognition of B1 level certificate. Ubiquitous questions are: If I pass the test and awarded the certificate, will the certificate be still valid by the time I graduate? Can I use this certificate to apply for postgraduate study after I graduate from university? Will I be able to sustain my English skills after 2 more years (because I'm not going to take any more English course from now to then), How many times can I take the B1-level test? If I pass the test at the end of the third semester, does it mean I have B1-level certificate or I have to take another test?

\subsection{Students' Suggestions}

The data show that the participants wish to see more coherence between what they learn and assessment. They also request for more self-assess resources which can prepare them better for B1-level tests. Specifically, practice tests mimicking the B1-level test are on strong demand. The students claim that the materials and sample tests their teachers give them are not enough and do not make them feel confident about their preparation for the test. They also need more practice to be able to talk and write in English. The participants suggest that the teaching pace be slower and the teachers spend more time (i.e., having more teacher-led hours) with them. Similar to what Walker (2008) found, the participants' responses also indicate that they have a wide range of learning objectives [14]. These learning objectives are found to fall unequally 
under three categories: language skills content which are closely associated with the textbooks, language skills required for their future job, and language skills for daily communication.

\section{Conclusion and Implications}

In a context where the CEFR stands as the central point of reference [13], little research on the use of the CEFR in the Vietnamese context is available [10], the application of the CEFR to the new general English curriculum requiring non-English majors to achieve B1 level has produced tremendous challenges [11]. This study has then provided insights into how French majors as key stakeholders of this policy perceive and understand the learning outcome they are expected to achieve.

The data analysis has shown that the French majored students surveyed are not fully aware of the required learning outcomes and show a strong orientation towards passing assessment rather than learning. This suggests that either students are not fully informed of the learning outcome they are required to achieve for each course or this information is not made accessible to them. The CEFR-based standards, especially level A1, A2 and B1 descriptors are not communicated effectively to the students. The use of B1-level of proficiency for gatekeeping purpose is neither well explained to nor negotiated with its key stakeholders. The lose connection between instruction contents and assessment practice makes the students demotivated.

From the findings, the following implications are made to help students understand better the CEFR-based learning outcomes required of them and facilitate their process of learning to achieve those outcomes. First and foremost, it is significant to express the required learning outcome in simple, concrete terms, which then makes it comprehensible and accessible to the students. The descriptions of the learning outcomes should be made available throughout the program for the students to refer to and to identify the degree of learning required to achieve those outcomes. Second, as the CEFR is often used to set standards which are not practical and hard to achieve by uninformed educational policy makers [1], the use of a specific standard, the CEFR B1 level of proficiency for making important decisions, for instance to decide whether undergraduates are eligible to be conferred university graduation degree should be clearly communicated to and even negotiated with the stakeholders. Third, where achievement assessment, teaching materials and language proficiency assessment are too much different in terms of task types, students need to be properly prepared both mentally and psychologically for the gatekeeping test. Self-assess learning resources and seminars as well as workshops on learning strategies, especially on self-regulated learning should also be provided.

\section{Acknowledgements}

This study is funded by Hue University.

\section{References}

[1] Alderson, J. C. (2007). The CEFR and the need for more research. The Modern Language Journal, 91, 659-663.

[2] Council of Europe (2001). Common European framework of reference for languages: Learning, teaching, assessment. Cambridge: Cambridge University Press.

[3] Desveaux, S. (2013). Guided learning hours. https://support.cambridgeenglish.org/hc/en-gb/articles/202838 506-Guided-learning hours. Retrieved on July $1^{\text {st }}, 2015$.

[4] Forbes, H., Duke, M., \& Prosser, M. (2001). Students' perceptions of learning outcomes from group-based, problem-based teaching and learning activities. Advances in Health Sciences Education, 6 (3), 205-217.

[5] Gosling, D. (2009). Learning outcomes debate. Accessed June 11 , 2013. http://www.davidgosling.net/userfiles/Learning\%20Outcomes \%20Debate(1).pdf.

[6] Hussey, T., \& Smith, P. (2008). Learning outcomes: A conceptual analysis. Teaching in Higher Education, 13 (1), $107-115$.

[7] MOET (2013a). MOET annual report. National Conference on Strategic Action Plan for the 2020 Project. Hanoi, October, 2013.

[8] MOET (2013b). Dispatch No. 7475 Guidance on learning outcomes for university programs. Hanoi, April, 2013.

[9] Nguyen, V. T. (2018). Project 2020 and professional development for high school EFL teachers in Vietnam. In K. Hashimoto \& V. Nguyen (Eds.) Professional development of English language teachers in Asia (pp. 95-108). New York: Routledge.

[10] Pham, T. H. N. (2013). Obstacles to primary school teachers' implementation of methodological innovations to teach English to young learners. Hue University Journal of Science, 80 (2), 35-46.

[11] Pham, T. H. N. (2017). Applying the CEFR to renew general English curriculum: Successes, remaining issues and lessons from Vietnam. In F. O' Dwyer et al. (Eds.) Critical, constructive assessment of CEFR-informed language teaching in Japan and beyond (pp. 97-117). Cambridge: Cambridge University Press.

[12] Pham, T. H. N. (2018). General English proficiency or English for teaching? The preferences of in-service teachers. RELC Journal, 49 (3), 339-352.

[13] Trim, J. (Ed.) (2001). Common European framework of reference for languages: Learning, teaching and assessment. User guide. Strasbourg: Council of Europe, available online: www.coe.int/lang-CEFR.

[14] Walker, P. (2008). What do students think they (should) learn at college? Student perceptions of essential learning outcomes. The Journal of Scholarship of Teaching and Learning, 8 (1), 45-60.

[15] Wright, S. (2002). Language education and foreign relations in Vietnam. In J. W. Tollefson (Ed.) Language policies in education: Critical issues (pp. 225-244). Mahwah, NJ: Lawrence Erlbaum. 